\title{
Anti-neutrophil antibodies in inflammatory bowel disease: prevalence and diagnostic role
}

\author{
G Cambridge, D S Rampton, T R J Stevens, D A McCarthy, M Kamm, B Leaker
}

\begin{abstract}
Anti-neutrophil antibodies have been shown in sera from patients with a variety of inflammatory diseases. Those reacting with components of neutrophil cytoplasm are associated with systemic vasculitis. Both nuclear and perinuclear staining patterns on human neutrophils have been reported using sera from patients with inflammatory bowel disease. We have evaluated the reactivity against human neutrophils of sera from 100 patients with inflammatory bowel disease, 14 disease controls, and 20 normal volunteers. Altogether 27/50 (54\%) sera from patients with ulcerative colitis contained antibodies that reacted with cytospun ethanol fixed neutrophils compared with $5 / 50(10 \%)$ from Crohn's disease $(p<0.001)$ and $0 / 34$ control sera $(p<0.001)$. All seven sera from patients with proctitis alone were negative $(p<0.01)$. There was no correlation between presence or titre of anti-neutrophil antibodies and either disease activity or treatment. Positive sera gave three different staining patterns on human neutrophils. The predominant pattern was perinuclear (17/32); 12 sera gave a cytoplasmic and three a homogeneous nuclear staining pattern. None of the patients or the controls had antibodies to myeloperoxidase, elastase, or serine proteinase 3 , all of which are recognised by anti-neutrophil cytoplasmic antibodies. Only $2 / 27$ sera positive by indirect immunofluorescence reacted with an extract of neutrophil primary granules. In conclusion, anti-neutrophil antibodies occur more commonly in ulcerative colitis than in Crohn's disease or control subjects and the antineutrophil antibodies found in inflammatory bowel disease are different from those associated with vasculitis.
\end{abstract}

London, W1

B Leaker

Department of Gastroenterology, The Royal London Hospital, London E1

D S Rampton

T R J Stevens

Queen Mary's and Westfield College, London E1

D A McCarthy

St Mark's Hospital, London EC1 M Kamm

Correspondence to: Dr G Cambridge, Department of Rheumatology, University College and Middlesex School College and Middlesex School
of Medicine, 40-50 Tottenham of Medicine, 40-50 Totten
Street, London W1P 9PG

Accepted for publication 30 August 1991 predominantly in the primary granules. Using a standard indirect immunofluorescent test we and others have found that ANCA give two distinct patterns on ethanol fixed human neutrophils either a coarse, granular cytoplasmic staining (c-ANCA) or a perinuclear staining pattern ( $\mathrm{p}$ ANCA) which is the result of the redistribution of granule constituents after fixation. ${ }^{3}$

Serum autoantibodies reacting with lympho- cytes, ${ }^{+}$colonic epithelial cells, ${ }^{56}$ and hepatic portal tracts ${ }^{7}$ have been reported in patients with inflammatory bowel disease. Other studies have described the presence of anti-neutrophil antibodies showing either a nuclear ${ }^{89}$ or perinuclear distribution ${ }^{10}$ in fixed neutrophils in patients with inflammatory bowel disease, a finding of particular interest in view of the proposal that Crohn's disease may represent a form of vasculitis affecting the gut."

Autoimmune mechanisms are thought to be involved in both vasculitis and inflammatory bowel disease. Although clear associations exist between disease activity and ANCA titre in a number of patients with vasculitis, studies in inflammatory bowel disease have provided conflicting results. ${ }^{910}$

We have examined sera from patients with inflammatory bowel disease for the presence of anti-neutrophil antibodies in an attempt to characterise their antigen specificity and relation to diagnosis, disease distribution and activity, and treatment.

\section{Methods}

Serum samples from patients with inflammatory bowel disease and three groups of control subjects were coded, aliquoted, and stored at $-20^{\circ} \mathrm{C}$ until analysed blind for antibodies to human neutrophils or to neutrophil components.

INFLAMMATORY BOWEL DISEASE PATIENTS

Crohn's disease and ulcerative colitis were diagnosed by conventional clinical, radiological, endoscopic, and histological criteria.

\section{Crohn's disease}

Fifty patients with Crohn's disease were studied. Their median age was 33 years (range 21-69) and 13 were men. The disease distribution of these patients is shown in Table II. Sixteen patients were taking oral corticosteroids, 20 sulphasalazine or a derivative, 4 topical steroids, 7 metronidazole, 5 azathioprine, and 17 were on no treatment (some patients were on more than one treatment). Activity of Crohn's disease was assessed using Harvey's simple clinical index ${ }^{12}$ adding one point for each of the following variables: haemoglobin $<12$ g/dl men, $<11$ women; erythrocyte sedimentation rate $>20$ $\mathrm{mm} /$ hour; platelet count $>500 \times 10^{9} / \mathrm{l}$; serum albumin $<35 \mathrm{~g} / \mathrm{l}$. A score for Harvey's index of 5 is equivalent to a National Cooperative Crohn's Disease Study Activity index ${ }^{13}$ of 150 and denotes active disease. In this study, Crohn's was deemed active for total scores $>5$. 
Ulcerative colitis

Fifty patients had ulcerative colitis. Their median age was 40 years (range 25-78) and 29 were men. The disease extent of these patients is shown in Table II. Sixteen were on steroids - 46 sulphasalazine or derivative, 14 topical steroids, 7 azathioprine, and 3 were not on treatment at the time of study. Disease activity in ulcerative colitis was estimated using the same laboratory variables as for Crohn's disease added to the following clinical score adapted from Harvey's index: well being (0-4), number of unformed stools on the previous day, rectal bleeding (0-3), sigmoidoscopic score of mucosal appearance (0-3), extraintestinal complications. A total score $>4$ was taken to indicate active ulcerative colitis.

\section{CONTROL SUBJECTS}

Normal controls

There were 20 healthy controls. Their median age was $34(21-65)$ years and seven were men.

\section{Untreated hospital controls (group I)}

This group comprised six patients (age 29 (20-59) years, two men) who were attending the gastroenterology outpatient clinic with untreated non-inflammatory disorders (irritable bowel syndrome (4), constipation (2)).

Inflammatory disease hospital controls (group II) This group comprised eight patients (age 29 (865) years, three men) attending hospital with bacterial diarrhoea (Shigella (2), Salmonella (2), Campylobacter (2)), pelvic inflammatory disease (1), and quiescent chronic active hepatitis (1)).

\section{PREPARATION OF NEUTROPHILS}

Human neutrophils were prepared from peripheral blood using standard techniques. ${ }^{1+}$ Briefly, blood from normal healthy volunteers was taken into heparinised containers. Neutrophils were separated by sedimentation with $1 \%$ dextran T500 (Pharmacia, Uppsala, Sweden) for 30 minutes at room temperature followed by centrifugation over Lympho-paque (Nygaard, Oslo, Norway). Red blood cells in the granulocyte containing pellet were lysed by hypotonic shock with distilled water. Purified neutrophils $(>95 \%)$ were either used to make cytospin preparations for indirect immunofluorescence or for subcellular fractionation to prepare substrates for enzyme linked immunosorbent assay (ELISA).

\section{INDIRECT IMMUNOFLUORESCENCE}

Cytospin preparations of neutrophils were air dried and stored wrapped in aluminium foil at $-70^{\circ} \mathrm{C}$. Before use, slides were brought to room temperature and fixed for 10 minutes with (a) absolute alcohol at $-4^{\circ} \mathrm{C}$, or (b) acetone at $-20^{\circ} \mathrm{C}$, or with (c) $2 \%$ paraformaldehyde in phospate buffered saline (PBS; pH 7.4) for 10 minutes followed by a further five minutes incubation in $95 \%$ ethanol $/ 5 \%$ PBS at $4^{\circ} \mathrm{C}$. The slides were then air dried for 15 minutes. For screening, sera was diluted $1 / 20$ in PBS with $10 \%$ normal goat serum (NGS), and for titration, doubling dilutions starting at 1/50 in the same diluent were used. All incubations were performed in humidified boxes at room temperature for 30 minutes. The slides were then washed with two changes of PBS for 10 minutes each, and antibodies binding to neutrophils were visualised using fluorescein conjugated sheep anti-human IgG (Wellcome Diagnostics) at a predetermined optimal titre of $1 / 50$ in $\mathrm{PBS} / 10 \%$ NGS. Slides were washed with two changes of PBS for 10 minutes each, mounted in glycerol, and read immediately by two independent observers. Known c- and p-ANCA positive sera from patients with vasculitis, two normal control sera, and controls without the addition of sera were included with each batch of sera tested. Positive control sera were verified by comparison with two other laboratories.

\section{ANTINUCLEAR ANTIBODIES}

Anti-nuclear antibodies were detected by standard techniques using $\mathrm{HeP}_{2}$ cells (Biodiagnostics Ltd) as substrate. A titre of $>1 / 20$ was regarded as positive. Standard positive control sera for autoantibodies to ssDNA, dsDNA, SS-A, SS-B, and centromere were obtained from the Centres for Disease Control, Atlanta, Georgia.

\section{PREPARATION OF SUBSTRATES FOR ELISA}

Purified neutrophils were incubated in the presence of di-isopropylfluorophosphate (DIFP; $2 \mathrm{mmol} / \mathrm{l})$, phenylmethylsulphonyl fluoride (1 $\mathrm{mmol} / \mathrm{l})$, and chymotrypsin $(20 \mathrm{mg} / \mathrm{ml})$ for 20 minutes at $4^{\circ} \mathrm{C}$, then disrupted by two 15 second cycles of sonication at $4^{\circ} \mathrm{C}$. After centrifugation at $1000 \mathrm{~g}$ for 10 minutes, the nuclear contents were discarded and the post nuclear supernatant retained. Post nuclear supernatant was fractionated by centrifugation ( $100000 \mathrm{~g}$ for 14 hours) on discontinuous sucrose gradients according to the method of Boregaard et al. ${ }^{15}$ Fractions containing the different subcellular organelles were separated according to increasing density as follows: cytosol, plasma membranes, secondary granules, and primary granules. A primary granule extract was prepared by disrupting the granules by sonication in the presence of a proteolytic enzyme inhibitor $(1 \mathrm{mmol} / \mathrm{l} \mathrm{DIFP})$. The contents were extracted with acetic acid $\mathrm{pH} 4.5$ and $0.5 \mathrm{~mol} / 1 \mathrm{NaCl} .^{16}$ This primary granule extract was subsequently used as substrate in ELISA tests. It was shown to contain serine protease 3 and elastase in a direct binding ELISA using monoclonal antibodies against serine protease 3 (Central Blood Transfusion Laboratory, Amsterdam; CLB-ANCA, clone number 12.8) and elastase (NP 57, Dako Laboratories). Myeloperoxidase was purified from primary granules according to the method of Mathieson et al. ${ }^{17}$ The purity index (A430/A280) of myeloperoxidase prepared for these studies was $0 \cdot 8$. 
TABLE I Antibodies to ethanol-fixed neutrophils in inflammatory bowel disease and control groups of patients

\begin{tabular}{|c|c|c|c|c|c|c|}
\hline & \multirow[b]{2}{*}{ No } & \multirow{2}{*}{$\begin{array}{l}\text { Positive } \\
\text { sera }(\%)\end{array}$} & \multicolumn{3}{|c|}{ Staining pattern } & \multirow{2}{*}{$\begin{array}{l}\text { Titre } \\
\text { (median (range)) }\end{array}$} \\
\hline & & & Perinuclear & Cytoplasmic & Nuclear & \\
\hline Ulcerative colitis & 50 & $27(54)$ & 15 & 10 & 2 & $1 / 50(1 / 20-1 / 1000)$ \\
\hline Proctitis alone & 7 & $0(0)$ & 0 & 0 & 0 & NA \\
\hline Crohn's disease & 50 & $5(10)$ & 2 & 2 & 1 & $1 / 50(1 / 20-1 / 200)$ \\
\hline Normal controls & 20 & $0(0)$ & 0 & 0 & 0 & NA \\
\hline Disease controls $(\mathrm{I})^{\star}$ & 6 & $0(0)$ & 0 & 0 & 0 & NA \\
\hline Disease controls (II) & 8 & $0(0)$ & 0 & 0 & 0 & NA \\
\hline
\end{tabular}

${ }^{\star}$ Disease control groups I and II as described in methods section. $\mathrm{NA}=$ not applicable.

ELISA'S

Antibodies to myeloperoxidase and primary granules were sought by direct binding ELISA tests. Briefly, myeloperoxidase or primary granule extract were coated onto half the wells of Maxisorb ELISA plates (Flow Laboratories) at concentrations of $1.5 \mu \mathrm{g} / \mathrm{ml}$ or $20 \mu \mathrm{g} / \mathrm{ml}$ respectively in $0 \cdot 1 \mathrm{~mol} / \mathrm{l}$ bicarbonate buffer ( $\mathrm{pH} \mathrm{9.6),} \mathrm{for}$ two hours at $37^{\circ} \mathrm{C}$. After two washes with PBS, free binding sites in the wells were blocked by incubation with $2 \%$ casein (BDH Ltd) and $1 \%$ gelatin (DIFCO Laboratories) in PBS. All subsequent incubations were for one hour at $37^{\circ} \mathrm{C}$, and plates were washed thrice with PBS containing $0 \cdot 1 \%$ Tween 20 (Sigma Chemical Co Ltd) between each stage of the test. The final two washes before adding substrate were with bicarbonate buffer $(0 \cdot 1 \mathrm{~mol} / \mathrm{l})$ at a $\mathrm{pH}$ of 9.6 . Uncoated wells served as controls for nonspecific binding for each serum to plastic. Sera were diluted $1 / 100$ in PBS containing $0.1 \%$ Tween 20 and $1 \%$ casein (BDH Ltd) for use. Antibody binding was detected using alkaline phosphatase conjugated goat anti-human immunoglobulins (Sigma) diluted 1/350 in PBS/ $0 \cdot 1 \%$ Tween 20 . Sigma 104 tablets were used as the source of substrate for the enzyme reaction. Plates were read on a Dynatech 4000 RI plate reader at wavelength of $410 \mathrm{~nm}$. The reaction was stopped by adding $1 \mathrm{~mol} / \mathrm{l} \mathrm{NaOH}$ to each well when the optical density in the positive control wells exceeded $1 \cdot 0$. Both ELISAs were standardised using serum containing antibodies to myeloperoxidase or c-ANCA (kindly provided by Dr Nils Rasmussen). Results were expressed as a percentage of the optical density given by the

TABLE II Relation between clinical features of patients with inflammatory bowel disease and presence of antineutrophil antibodies

\begin{tabular}{lll}
\hline & \multicolumn{2}{c}{$\begin{array}{l}\text { No of patients (\%) with antibody } \\
\text { positive sera }\end{array}$} \\
\cline { 2 - 3 } Clinical features & Ulcerative colitis & Crohn's disease \\
\hline Disease activity: & $12 / 22(55)$ & $0 / 16(0)$ \\
$\quad$ Active & $15 / 28(54)$ & $5 / 34(15)$ \\
$\quad$ Inactive & $5 / 16(31)$ & $0 / 16(0)$ \\
Systemic steroid therapy: & $22 / 34(65)$ & $5 / 34(15)$ \\
$\quad$ Yes & $0 / 7(0)^{\star}$ & \\
$\quad$ No & $13 / 19(68)$ & N/A \\
Disease extent: & $10 / 17(65)$ & \\
$\quad$ Proctitis & $4 / 7(57)$ & \\
$\quad$ Left sided & & $2 / 21(10)$ \\
$\quad$ Subtotal & & $2 / 11(18)$ \\
Dotal & Nisease site: & $1 / 18(6)$ \\
$\quad$ Small bowel only & & \\
$\quad$ Ileocolonic & & \\
Colorectal & &
\end{tabular}

${ }^{\star} \mathrm{p}<0.01$ from remainder of patients with ulcerative colitis (Fisher's exact test) standard sera, after subtracting the background binding of individual sera of wells uncoated with antigen.

Antibodies to serine protease 3 and neutrophil elastase were detected using a 'capture' ELISA after the method of Goldschmedding et al. ${ }^{18}$ In each ELISA, positive sera were regarded as those with a $\%$ binding greater than 3 SD above the mean of 10 normal sera included in the same experiment.

\section{STATISTICS}

Comparisons of the prevalence and titres of antineutrophil antibodies in different subject groups were made using Fisher's exact test, $\chi^{2}$ analysis and Student's $t$ test. Results of the primary granule extract (PGE) ELISA were analysed using the Mann-Whitney U test.

\section{Results}

\section{ANTINEUTROPHIL ANTIBODIES}

Control sera from normal individuals and patients without inflammatory bowel disease were all negative for antibodies to neutrophils and nuclear antigens by indirect immunofluorescence. These sera were also negative in ELISA tests which detected antibodies to neutrophil granule components. In ulcerative colitis, 54\% (27/50) sera were positive for antineutrophil antibodies on ethanol fixed slides $\left(\mathrm{p}<0.001\right.$ from controls, $\chi^{2}$ test; Table I) with a median titre of $1 / 50$ (range from $1 / 20$ to $1 / 1000$ ). There was no correlation between frequency of antibody positivity and disease activity or systemic treatment with steroids (Table II). Patients with proctitis only were negative $(\mathrm{p}<0.01)$ when compared with other patients with ulcerative colitis (Table II)

In Crohn's disease, $5 / 50$ (10\%) of sera were positive $(p<0.001$ compared with ulcerative colitis) (Table I), again with no significant relation to disease activity or steroid treatment. Only $1 / 18(6 \%)$ patients with Crohn's colitis had a positive serum $(\mathrm{p}<0.001$ compared with ulcerative colitis; Table II).

\section{STAINING PATTERNS ON FIXED NEUTROPHILS}

Three different patterns of reactivity were seen in cytospin preparations of human neutrophils fixed in ethanol (Fig 1A-C, Table III). The predominant pattern was intense perinuclear staining around neutrophil nucleii (17/32; Fig 1A). The nuclei of monocytes, lymphocytes, and other leukocyte nuclei were not stained. Staining was also noted to radiate into the cytoplasm of the neutrophils to varying extents with different sera and preparations, although the predominant staining pattern was highly reproducible when neutrophils from different donors were used. In contrast, known p-ANCA containing sera from patients with vasculitis gave clearly defined perinuclear staining. ${ }^{3}$ In addition, a homogeneous cytoplasmic staining was given by 12 sera from patients with inflammatory bowel disease. This was dense and non-granular (Fig 1B), unlike that shown by c-ANCA positive sera from patients 


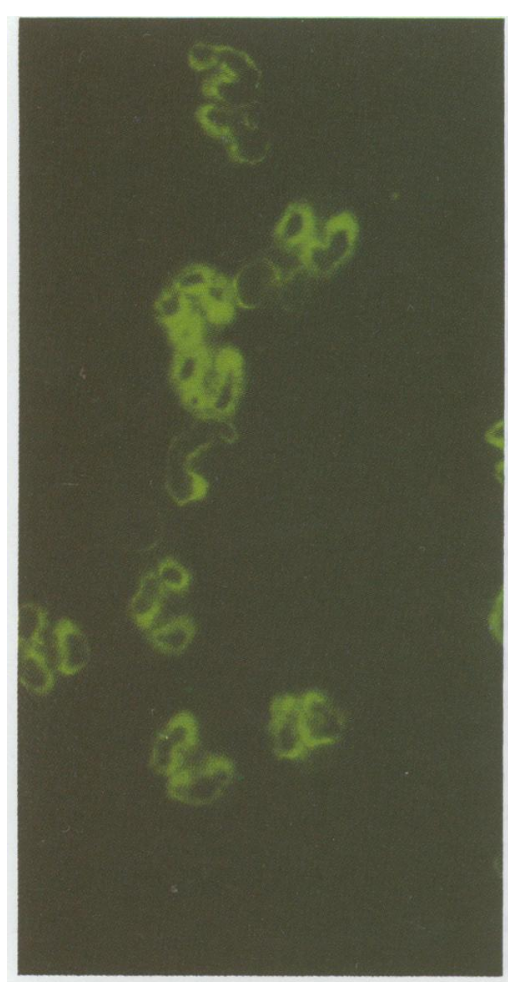

(a)

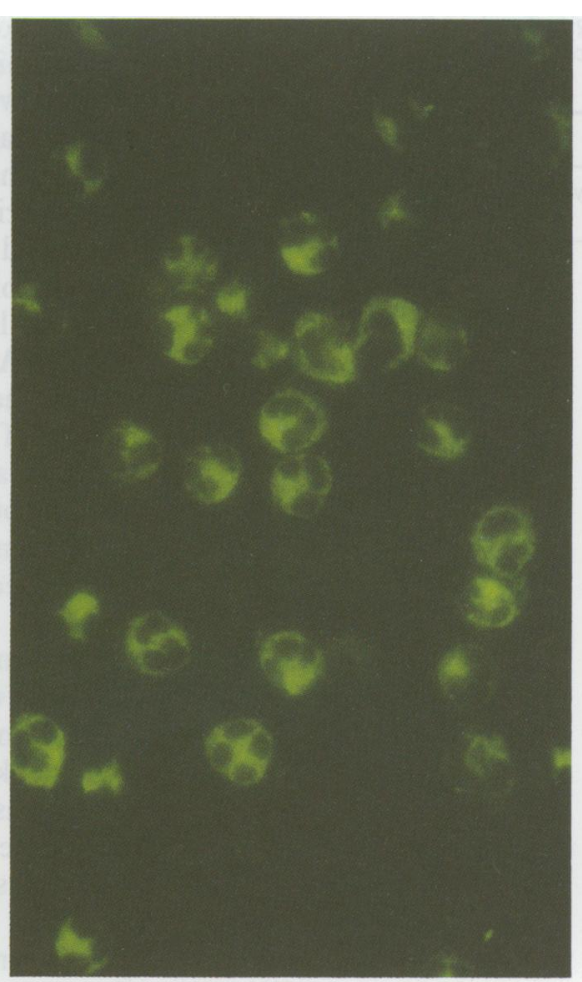

(b)

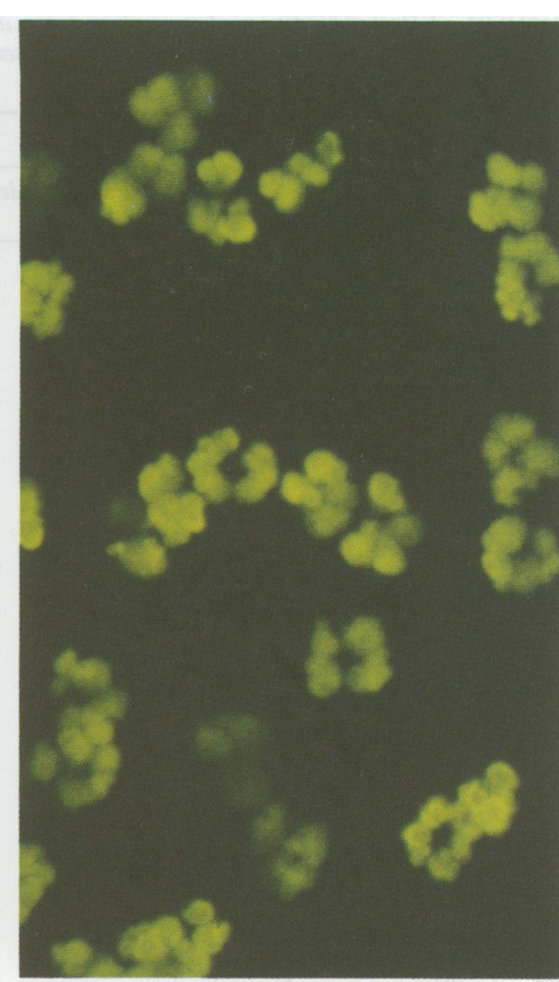

(c)

Figure 1: Photomicrograph showing three different patterns of staining of cytospin preparations of ethanol fixed human neutrophils by inflammatory bowel disease sera: $(A)$ perinuclear, $(B)$ cytoplasmic, and $(C)$ nuclear.

with vasculitis, which is characteristically coarse, granular, and centrally accentuated. The third staining pattern seen was diffuse nuclear staining of all leukocyte nucleii (Fig 1C). In all cases this was shown to be due to the presence of antinuclear antibodies (ANA) in sera, the titre on $\mathrm{HeP} 2$ cells exceeding that of neutrophils by at least two doubling dilutions (Table III). The titre of anti-neutrophil antibodies on ethanol fixed neutrophils by inflammatory bowel disease sera ranged from $1 / 20-1 / 1000$ (Table II). Half of those with low titres (positive at 1/20 dilution only) gave a diffuse cytoplasmic staining pattern (Table III).

\section{ANTI-NUCLEAR ANTIBODIES}

A total of six patients had detectable anti-nuclear antibodies on $\mathrm{HeP} 2$ cells. In three patients, the titre of anti-nuclear antibodies was at least twofold lower than that given by the same sera on ethanol fixed neutrophils, two of which gave a cytoplasmic pattern and one a perinuclear one. It was therefore likely that autoantibodies of at least two specificities were present in these sera.

\section{EFFECT OF FIXATIVES ON STAINING PATTERNS}

The choice of fixative for the measurement of leukocyte autoantibodies has been shown to influence both the distribution and frequency of staining. ${ }^{319}$ This is illustrated in Table III, where the result and staining pattern of sera positive on ethanol-fixed cells were compared with those of the same sera on acetone or paraformaldehyde/ ethanol fixed substrates. Eighteen of these 32 sera remained positive on acetone fixed cells but some changes in the distribution of staining was seen. Sixteen of the sera positive on both acetone and ethanol fixed neutrophils had given titres exceeding 1/50 on ethanol fixed cells. These results suggest that acetone fixation reduced the sensitivity of the test.

When cytospin preparations were prefixed in $2 \%$ formaldehyde in PBS and then in cold ethanol, 21/32 sera positive on cells fixed with ethanol alone sera lost their ability to bind to neutrophils (Table III).

\section{ELISAS}

ANCA in sera from patients with vasculitis

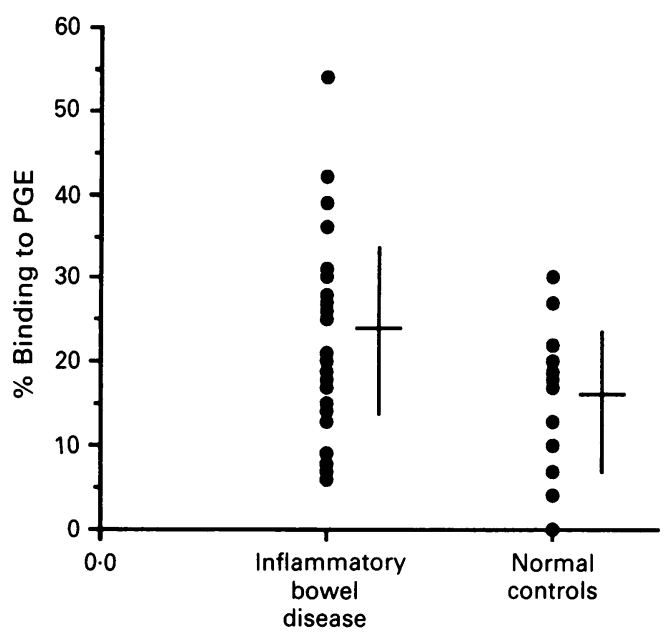

Figure 2: Antibodies to neutrophil primary granule extract $(P G E)$ in sera from 20 normal individuals and 27 with inflammatory bowel disease detected using an ELISA. Results are expressed as a percentage of a standard positive control serum. Mean values for each group are indicated with horizontal bars. The p value comparing inflammatory bowel disease sera results with controls was $<0.001$ (Mann-Whitney $U$ test). 
TABLE III Effect of fixative used on result and staining pattern by inflammatory bowel disease sera on cytospin preparations of neutrophils. The presence of anti-nuclear antibodies in the same sera are also shown

\begin{tabular}{|c|c|c|c|c|}
\hline & \multicolumn{3}{|c|}{ Fixation method } & \multirow[b]{2}{*}{$\begin{array}{l}\text { Result and staining pattern on } \\
\text { HeP2 cells }\end{array}$} \\
\hline & Ethanol & Acetone & $\begin{array}{l}\text { Paraformaldehydel } \\
\text { ethanol }\end{array}$ & \\
\hline 1 & $\mathrm{C}$ & - & - & - \\
\hline $2^{\star}$ & $\mathrm{c}$ & $\mathrm{N}$ & - & ++ Homogeneous nuclear \\
\hline 3 & PN & - & - & - \\
\hline $4 \dagger$ & PN & $\mathbf{N}$ & N/PN & - \\
\hline $5+$ & $\mathbf{N}$ & - & - & ++ Homogeneous nuclear \\
\hline $6+$ & $\mathrm{C}$ & PN & - & - \\
\hline $\begin{array}{l}7^{\star} \\
8\end{array}$ & $\begin{array}{l}\mathrm{C} \\
\mathrm{C}\end{array}$ & C & $\underset{\mathrm{PN}}{\mathrm{C}}$ & $\overline{-}$ \\
\hline 9 & $\mathrm{c}$ & $\overline{\mathrm{PN}}$ & $\mathrm{CN}$ & - \\
\hline 10 & $\mathrm{C}$ & - & $\mathrm{c}$ & + Nucleolar \\
\hline $11 \dagger$ & $\mathrm{C}$ & $\mathrm{C}$ & - & - \\
\hline $12^{\star}$ & $\mathrm{C}$ & $\mathrm{C}$ & - & - \\
\hline 13 & $\mathrm{C}$ & - & - & - \\
\hline $14 \dagger$ & $\mathrm{C}$ & - & $\mathrm{C}$ & - \\
\hline $15^{\frac{1}{}}$ & $\mathrm{C}$ & $\mathrm{C}$ & - & - \\
\hline $16^{\star}$ & PN & $\mathrm{PN}$ & C & - \\
\hline $17 \dagger$ & PN & $\mathrm{N}$ & PN & + Speckled nuclear \\
\hline 18 & $\mathrm{PN}$ & - & $\mathrm{C}$ & - \\
\hline 19 & PN & - & - & - \\
\hline 20 & PN & - & - & - \\
\hline $21^{\star}$ & $\mathrm{PN}$ & PN & - & - \\
\hline $22 \dagger$ & $\mathrm{PN}$ & - & - & - \\
\hline $23+$ & PN & PN & - & - \\
\hline $24 \dagger$ & PN & PN & - & - \\
\hline $25^{\star}$ & PN & $\mathrm{N}$ & - & - \\
\hline $26^{\star}$ & PN & PN & - & - \\
\hline $27 \dagger$ & PN & - & - & - \\
\hline $28 t$ & PN & - & - & - \\
\hline 29 & PN & PN & - & - \\
\hline $30^{\star}$ & PN & $\mathrm{N}$ & - & - \\
\hline $31^{\star}$ & $\mathrm{N}$ & $\mathrm{N}$ & N/PN & ++ Homogeneous nuclear \\
\hline $32 \dagger$ & $\mathrm{N}$ & - & $\mathrm{C}$ & + Nucleolar \\
\hline
\end{tabular}

*: $>1 / 200$ on ethanol fixed neutrophils

$t:>1 / 50$ on ethanol fixed neutrophils

C: cytoplasmic (Fig 1A); PN: perinuclear (Fig 1B); N: nuclear (Fig 1C)

recognise enzymes present in neutrophil primary granules. Twenty seven inflammatory bowel disease sera positive for anti-neutrophil antibodies by indirect immunofluorescence and 20 normal controls were tested in an ELISA for the presence of antibodies to primary granule extract (Fig 2). Although the inflammatory bowel disease sera gave significantly higher binding $(p<0.001$, Mann-Whitney U test) than normal controls, only two sera from patients with ulcerative colitis (sera numbers 7 and 15 in Table III) showed a percentage binding to primary granule extract greater than the mean $(3 \mathrm{SD} ; 16 \pm 8)$ of normal control samples. Both sera had produced a cytoplasmic staining pattern on ethanol and acetone fixed neutrophils, with titres greater than $1 / 200$.

None of the 27 inflammatory bowel disease sera contained antibodies to myeloperoxidase, serine protease 3 , or neutrophil elastase (data not shown).

\section{Discussion}

In patients with inflammatory bowel disease, we have demonstrated three distinct patterns of serum IgG reactivity with human neutrophils. Most were perinuclear in distribution but cytoplasmic and nuclear patterns were also seen. These autoantibodies were present in over $50 \%$ of sera from patients with ulcerative colitis but in only $10 \%$ taken from those with Crohn's disease.

Autoantibodies reacting with several different tissues have been reported in patients with inflammatory bowel disease. ${ }^{+7}$ Recently, circulating antibodies thought to react with portal tracts of obstructed human liver have been shown to be directed against the nuclei of neutrophils present in this tissue. ${ }^{9}$ These antibodies were termed ANNA (anti-neutrophil nuclear antibodies) by the authors who concluded that they may be analogous to granulocyte specific anti-nuclear antibodies (GS-ANA) described by others in sera from patients with rheumatoid arthritis, Felty's syndrome, and systemic lupus erythematosus. ${ }^{8}$ The incidence of 'GS-ANA' in patients with inflammatory bowel disease has ranged from $0 \%$ in an unselected group of colitics $^{20}$ to $98 \%$ of patients with recently active ulcerative colitis. ${ }^{9}$ However, in our and other studies using an indirect immunofluorescence technique, the neutrophil antigens recognised by inflammatory bowel disease sera seem to be cytoplasmic or perinuclear, not nuclear in distribution. ${ }^{1021}$ This could reflect the different visualisation techniques used for detection of anti-neutrophil antibodies. In the study by Snook et al, ${ }^{9}$ an immunoperoxidase technique was employed. When either 3-3 diamino benzidine or 3 amino 9 ethylcarbazole are used as substrates in this test, detection of positive reactions are due to precipitation of insoluble colour products. With the indirect immunofluorescence technique, there is direct visualisation of antibody binding. Therefore, although increased sensitivity through amplification of a positive signal is an advantage of using the immunoperoxidase technique, distortion of the intracellular location of an antigen is more likely to be a problem

A cytoplasmic location for anti-neutrophil antibody binding was also suggested by the significantly higher binding of indirect immunofluorescence positive inflammatory bowel disease sera to neutrophil primary granules in an ELISA, compared with normal controls. However, only two sera gave a strongly positive reaction. This suggests that the antigens recognised by anti-neutrophil antibodies in inflammatory bowel disease are either not present in high enough concentrations in the primary granule extract for detection in the ELISA test used or may reflect low level contamination of the granule extract with other cytosolic components which are recognised by antibodies present in inflammatory bowel disease sera.

Of those sera with only weak (titre of $1 / 20$ ) staining of ethanol fixed neutrophils, $5 / 12$ gave a cytoplasmic staining pattern. This could be due to immune complexes present in sera binding to $F c$ receptors on neutrophils, giving a false positive result. ${ }^{212}{ }^{23}$ In conditions such as rheumatoid arthritis and systemic lupus erythematosis, however, where high levels of circulating immune complexes are often found in sera, such 'false positive' ANCA results rarely occur. ${ }^{14}$ Although all sera used in our study were centrifuged before use, immune complex binding to Fc receptors on neutrophils may explain some of the weakly positive staining of neutrophil cytoplasm reported here. None of the inflammatory bowel disease sera reacted with serine protease 3 , the antigen recognised by most c-ANCA positive sera from patients with vasculitis. ${ }^{.+}$

The predominant pattern of neutrophil staining by inflammatory bowel disease sera in our studies was, however, perinuclear. The peri- 
nuclear pattern seen could be due to leakage of nuclear antigens into the cytoplasm ${ }^{19}$ or a cytoplasmic component associating with the nucleus. ${ }^{3}$ In patients with vasculitis, the p-ANCA staining pattern is usually attributable to the presence of antibodies to myeloperoxidase, although antibodies to other primary granule constituents such as elastase, lactoferrin, and cathepsin G can give similar patterns on ethanol fixed neutrophils. ${ }^{25}$ We did not find antibodies to myeloperoxidase or elastase in inflammatory bowel disease era. Antibodies to cathepsin $G$ and elastase were also reportedly absent from inflammatory bowel disease sera in another recent study. ${ }^{21}$ Serum antibodies to myeloperoxidase were found in 1 of 20 patients with ulcerative colitis and Crohn's disease ${ }^{10}$ and Duerr et al ${ }^{21}$ claimed (data not shown) that sera from a subset of patients with ulcerative colitis and primary sclerosing cholangitis giving a perinuclear staining pattern by indirect immunofluorescence were associated with the presence of antimyeloperoxidase antibodies. However, the antigens responsible for most of the perinuclear staining pattern shown by inflammatory bowel disease sera do not seem to be those recognised by $\mathrm{p}$-ANCA in vasculitis.

A diffuse, nuclear staining pattern of ethanol fixed neutrophils by inflammatory bowel disease sera was also seen. In most cases this was due to the presence of anti-nuclear antibodies present in the sera, as detected by positive staining of $\mathrm{HeP} 2$ cell nuclei. Anti-nuclear antibodies have previously been shown to give variable staining patterns of human granulocytes. ${ }^{19}$

In patients with vasculitis, formalin fixation does not alter binding of ANCA to neutrophils, merely preventing the redistribution of some primary granule components to the perinuclear site. ${ }^{3}$ Saxon $e t a l^{10}$ claimed that fixation with paraformaldehyde, glutaraldehyde, and methanol did not change the staining pattern of inflammatory bowel disease sera on human neutrophils. In contrast, our studies showed that paraformaldehyde fixation ablated the reactivity of $60 \%$ of inflammatory bowel disease sera with human neutrophils. This could be due to destruction of antigenic epitopes by formaldehyde or, as discussed by Wiik, ${ }^{19}$ the loss of low molecular weight autoantigens highly soluble in PBS from the cell when exposed to fixatives in saline solutions. Alternatively, the disparity between our results and those previously reported ${ }^{10}$ could simply reflect methodological differences such as length of exposure to, or $\mathrm{pH}$ of, the paraformaldehyde used as fixative.

The subclass of anti-neutrophil antibodies measured in this and most other studies has been IgG. ${ }^{1021}$ Snook et $a l^{9}$ reported that IgM and IgG ANNA were also present in inflammatory bowel disease sera although the dominant subclass was IgG. We also detected $\operatorname{IgM}$ and IgA antineutrophil antibodies in inflammatory bowel disease sera, although they were of low titre and present only when high titre IgG antibodies were also present (data not shown).

In Crohn's disease, the low prevalence of antineutrophil antibodies makes the test unlikely to be of value as a diagnostic marker. However, the relatively high prevalence in ulcerative colitis suggests that the test may be of some use in differentiating this condition from Crohn's colitis, localised proctitis, and other causes of diarrhoea. There was no association between the presence of circulating antibodies to human neutrophils in inflammatory bowel disease patients and disease activity or drug treatment. Saxon et $a l^{10}$ concluded that anti-neutrophil antibodies in Crohn's disease occurred only in patients with disease affecting the colon. In contrast, we found such antibodies in two patients with Crohn's disease apparently confined to the small bowel and in only one subject with Crohn's colitis.

In conclusion, most inflammatory bowel disease sera that react with ethanol fixed human neutrophils give a perinuclear or clearly cytoplasmic staining pattern. Although ANCA assume similar staining patterns, the antibodies being directed against constituents of neutrophil primary granules, it is unclear whether the neutrophil antigens recognised by inflammatory bowel disease sera are nuclear or cytoplasmic in distribution. The staining patterns described by us and others could equally be interpreted as leakage of soluble antigens from the nucleus. More sensitive techniques are required to determine the location and identity of inflammatory bowel disease associated anti-neutrophil antigens. Dr G Cambridge and support for this work were funded by the St
Peter's Trust. Dr T R J Stevens is funded by the National Council for Crohn's and Colitis. Dr I Laurenson and N I Simmonds kindly for Crohn's and Colitis. Dr I Laurenson and N J Simmonds kindly segal and G H Neild for their support and helpful discussions relating to this project.

1 Jennette JC, Falk RJ. Anti-neutrophil cytoplasmic autoantibodies. $N$ Engl f Med 1988; 319: 1417.

2 Lai KN, Jayne DRW, Brownlee A, Lockwood CM. The specificity of anti-neutrophil cytoplasm autoantibodies in systemic vasculidities. Clin Exp Immunol 1990; 82: 233-7.

3 Falk RJ, Jennette JC. Anti-neutrophil cytoplasmic autoantibodies with specificity for myeloperoxidase in patients with bodies with specificity for myeloperoxidase in patients with systemic vasculitis and idiopathic necrotising and crescent

4 Korsmeyer SJ, Williams RG Jr. Lymphocytotoxic antibodies in ulcerative colitis. $N$ Engl f Med 1975; 293: 1117-20.

5 Fiocchi C, Roche JK. High prevalence of antibodies to intestinal epithelial antigens in patients with inflammatory bowel disease and their relatives. Ann Intern Med 1989; 110 : 786-94

6 Broberer O, Perlmann P. Antibodies in human ulcerative colitis. F Exp Med 1963; 110: 657-74

7 Chapman RW, Cottone M, Selby WS, Shepherd HA Sherlock S, Jewell DP. Serum autoantibodies, ulcerative colitis and primary cholangitis. Gut 1986; 27: 86-91

8 Nielson H, Wiik A, Elmgreen J. Granulocyte specific antinuclear antibodies in ulcerative colitis. Acta Pathol Microbiol Immunol Scand 1983; 91: 23-6.

9 Snook JA, Chapman RW, Fleming K, Jewell DP. Antineutrophil nuclear antibody in ulcerative colitis, Crohn's neutrophil nuclear antibody in ulcerative colitis, Crohn's
disease and primary sclerosing cholangitis. Clin Exp disease and primary

10 Saxon A, Shanahan F, Landers C, Ganz T, Targan SA Distinct subset of antineutrophil cytoplasmic antibodies is associated with inflammatory bowel disease. $\mathcal{F}$ Allergy Clin Immunol 1990; 86: 202-10.

11 Wakefield AJ, Sawyer AM, Dhillon AP, Pittilo RM, Rowles PM, Lewis AAM, et al. Pathogenesis of Crohn's Disease; multifocal gastrointestinal infarction. Lancet 1989; ii: $1057-$ 62.

12 Harvey RF, Bradshaw JM. A simple index of Crohn's disease activity. Lancet 1980; i: 514-5.

13 Best WR, Becktel JM, Singleton JW, Kern F. Development of a Crohn's disease activity index. Gastroenterology 1976; 70: 439-45.

14 Venning MC, Quinn A, Broomhead V, Bird AG. Antibodies directed against neutrophils (c-ANCA and p-ANCA) are of directed against neutrophils (c-ANCA and p-ANCA) are of
distinct diagnostic value in systemic vasculitis. $Q \mathcal{F}$ Med distinct diagnostic

15 Boregaard N, Heiple JM, Simons FR, Clark RA. Subcellular localisation of the b-cytochrome component of the human neutrophil microbicidal oxidase translocation during activation. F Cell Biol 1983; 97: 52-61.

16 Goldschmeding R, van der Schoot CE, ten Bokkel Huinink D, Hack CE, van den Ende ME, Kallenberg CGM, et al Wegener's granulomatosis autoantibodies identify a novel 
diisoproppylfluorophosphate binding protein in the lysosomes of normal human neutrophils. $\mathcal{f}$ Clin Invest 1989; 84: $1577-87$

17 Mathieson NR, Wong PS, Travis J. Isolation and properties of human myeloperoxidase. Biochemistry 1981; 20: 325-30.

18 Goldschmeding R, van der Schoot CE, van der Snoek MA, Kr van dem Borne AEG. A monoclonal antibody against the 29 kD ANCA antigen; application as catching antibody in a sandwich ELISA for ANCA detection. Proc First Int Workshop on ANCA: APMIS 1988; 97 (suppl 6): 47.

19 Wiik A. Granulocyte specific antinuclear antibodies. Allergy 1980; 35: 263-89.

20 Faber V, Elling P. Leucocyte specific anti-nuclear antibodies in patients with Felty's syndrome, rheumatoid arthritis, systemic lupus erythematosus and other diseases. Acta Med
Scand 1966; 179: 257-67.

21 Duerr RH, Targan SR, Landers CJ, Larusso NF, Lindsay $\mathrm{KL}$, Wiesner RH, et al. Neutrophil cytoplasmic antibodies: A link between primary sclerosing cholangitis and ulcerative colitis. Gastroenterology 1991; 100: 1385-91.

22 Koderisch J, Andrassy K, Rasmussen N, Hartmann M, Tilgen W. 'False-positive' anti-neutrophil cytoplasmic antibodies in HIV infection. Lancet 1990; 335: 1227-8.

23 Davenport A, Grant PJ. False-positive autoantibodies in HIV infection. Lancet 1990; 336: 317-8

24 Ludemann J, Utecht B, Gross WL. Anti-neutrophil cytoplasm antibodies in Wegener's Granulomatosis recognise an antibodies in Wegener's Granulomatosis recognise an

25 Falk RJ. ANCA-associated renal disease. Kidnev Int 1990; 38: 998-1010. 